OPEN ACCESS

Edited by: Elias Georges,

McGill University, Canada

Reviewed by:

Sahil Sharma,

Sloan Kettering Insitute, United States

Guozheng Huang,

Anhui University of Technology, China

*Correspondence:

Feng Gao

rggaofeng@sdu.edu.cn

Specialty section:

This article was submitted to

Pharmacology of Anti-Cancer Drugs,

a section of the journal

Frontiers in Pharmacology

Received: 25 October 2021

Accepted: 22 November 2021

Published: 16 December 2021

Citation:

Hou H, Qu B, Su C, Hou G and Gao F (2021) Design, Synthesis and AntiLung Cancer Evaluation of 1, 2, 3Triazole Tethered DihydroartemisininIsatin Hybrids.

Front. Pharmacol. 12:801580. doi: 10.3389/fphar.2021.801580

\section{Design, Synthesis and Anti-Lung Cancer Evaluation of 1, 2, 3-Triazole Tethered Dihydroartemisinin-Isatin Hybrids}

\author{
Haodong Hou, Bin Qu, Chen Su, Guihua Hou and Feng Gao* \\ Key Laboratory for Experimental Teratology of the Ministry of Education and Center for Experimental Nuclear Medicine, School of
} Basic Medical Sciences, Cheeloo College of Medicine, Shandong University, Jinan, China

A series of 1,2,3-triazole tethered dihydroartemisinin-isatin hybrids 8a-c and 9a-k were designed and synthesized. Their antiproliferative activity against A549, doxorubicinresistant A549 (A549/DOX) as well as cisplatin-resistant A549 (A549/DDP) lung cancer cell lines was also investigated in this study. All hybrids (half maximal inhibitory concentration/ $/ \mathrm{IC}_{50}$ : $\left.7.54-73.8 \mu \mathrm{M}\right)$ were more potent than the parent drug dihydroartemisinin $\left(\mathrm{IC}_{50}: 69.4-88.0 \mu \mathrm{M}\right)$ and also non-cytotoxic towards mouse embryonic fibroblast cells $\mathrm{NIH} / 3 \mathrm{~T} 3\left(\mathrm{IC}_{50}:>100 \mu \mathrm{M}\right)$. The structure-activity relationships illustrated that the substituents on C-3 and C-5 position of isatin moiety influenced the activity significantly. Imine at C-3 position decreased the activity, whereas fluoro at C-5 position enhanced the activity. In particular, hybrids 8a,c $\left(\mathrm{IC}_{50}: 7.54-12.1 \mu \mathrm{M}\right)$ and $9 \mathrm{i}\left(\mathrm{IC}_{50}\right.$ : 9.10-15.9 $\mu \mathrm{M})$ were comparable to cisplatin $\left(\mathrm{IC}_{50}\right.$ : $7.54-15.9 \mu \mathrm{M}$ vs $\left.9.38-19.7 \mu \mathrm{M}\right)$ against $A 549$ and A549/DOX, but 4.6-7.6 folds more potent than that of cisplatin $\left(\mathrm{IC}_{50}\right.$ : $8.77-14.3 \mu \mathrm{M}$ vs $\left.66.9 \mu \mathrm{M}\right)$ against A549/DDP cells. Moreover, hybrids 8a,c exhibited excellent stability (liver microsomes: 68-83\%) in mouse/human microsomes and good pharmacokinetic properties, demonstrating their potential as a novel anti-lung cancer chemotherapeutic candidates.

Keywords: artemisinin, dihydroartemisinin, isatin, 1,2,3-triazole, hybrid molecules, multidrug resistance, structureactivity relationship

\section{INTRODUCTION}

Lung cancer represents one of the most malignant tumors with the high morbidity and mortality, and non-small cell lung cancer (NSCLC, accounts for $80-85 \%$ of lung cancer cases) is the most aggressive type of lung cancer (Willis et al., 2019; Sławiński et al., 2020). Lung cancer is responsible for around $20 \%$ of all cancer deaths with an estimated 1.8 million new cases and 1.6 million deaths annually (Oak et al., 2012; Hirsch et al., 2017). The pace of the annual decline in lung cancer mortality doubled from $2.4 \%$ (during 2009 through 2013) to $5.0 \%$ (during 2014 through 2018) due to the advances in diagnostics and therapy, and this trend coincides with the steady declined incidence (2.2-2.3\%) (Siegel et al., 2021; Wen et al., 2021). However, even lung cancer is diagnosed in the early stages, around one in four patients develop relapse and most of them die from recurrent disease (the overall 5-years survival rates are only around 15\%) (Gray et al., 2019; Bade and Dela Cruz, 2020; Coakley and Popat, 2020; Schegoleva et al., 2021). Multidrug resistance, caused by various simulations such as off-target effect in G2/M arrest (Nascimento et al., 2017), insufficient production of apoptotic factors (Chen et al., 2014), and enhanced DNA repair 


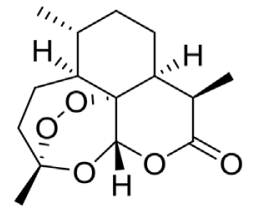

artemisinin

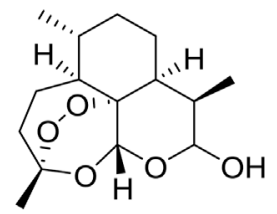

dihydroartemisinin<smiles>O=C1Nc2ccccc2C1=O</smiles>

isatin

FIGURE 1 | Chemical structures of artemisinin, dihydroartemisinin and isatin

(Nascimento et al., 2017; Kang et al., 2019), is also considered as a major challenge for cancer treatment (Yan et al., 2013; He et al., 2015; He et al., 2016). The absence of effective anti-lung cancer drugs, especially those against drug-resistant lung cancer, make the mortality of lung cancer still high. Therefore, it is urgent to develop novel drug candidates with high activity and efficacy against lung cancer, especially drug-resistant lung cancer.

Artemisinin derivatives such as dihydroartemisinin (DHA, Figure 1) and artesunate, which own a unique sesquiterpene endoperoxide lactone moiety, could form highly reactive free radicals including reactive oxygen species (ROS) in the presence of ferrous ion ( $\mathrm{Fe}^{\mathrm{II}}$ ) (Yu et al., 2019; Gao et al., 2020). Fe $\mathrm{Fe}^{\mathrm{II}}$ accumulated in cancer cells is as much as 1,000 times that in normal cells, and artemisinin derivatives exhibit potential anticancer efficacy without significant cytotoxicity to normal cells, making these compounds far different from conventional chemotherapy (Dai et al., 2017; Kiani et al., 2020). The mechanistic studies elucidated that artemisinin derivatives could exert the anticancer activity via multiple mechanisms including inhibition of angiogenesis, apoptosis, cell cycle arrest, disruption of cell migration, and modulation of nuclear receptor responsiveness (Li et al., 2021; Zhu et al., 2021). Moreover, artemisinin derivatives could remarkably influence the growth of lung tumor in vivo through inhibiting Wnt/ $\beta$-catenin pathway, revealing the potential application of artemisinin derivatives as a novel class of therapeutic drugs for lung cancer (Tong et al., 2016; Zhang et al., 2021).

Isatin derivatives have the potential to act on a variety of drug targets like histone deacetylase, $\beta$-carbonic anhydrase, tyrosine kinase and tubulin, and the isatin-based nintedanib has already been approved for the lung cancer therapy (Sharma et al., 2014; Ding et al., 2020; Hou et al., 2020; Nath et al., 2021; Varpe et al., 2021). Therefore, isatin derivatives are also considered as useful templates for the development of novel anti-lung cancer agents.

Molecular hybridization represents one of the common strategies to discover new drugs since hybrid molecules usually own dual/multiple modes of action that can overcome drug resistance, enhance the efficacy, reduce adverse effects, and improve pharmacokinetic and pharmacodynamic properties (Singh et al., 2013; Nepali et al., 2014; Saadeh and Mubarak, 2017; Feng et al., 2020). Accordingly, hybridization of dihydroartemisinin with isatin may open a door to develop potential drug candidates against lung cancers including drugresistant forms.

It is reported triazoles hold potential cytotoxic towards cancer cells, which attracted us towards the selection of 1,2,3-triazole as a linker

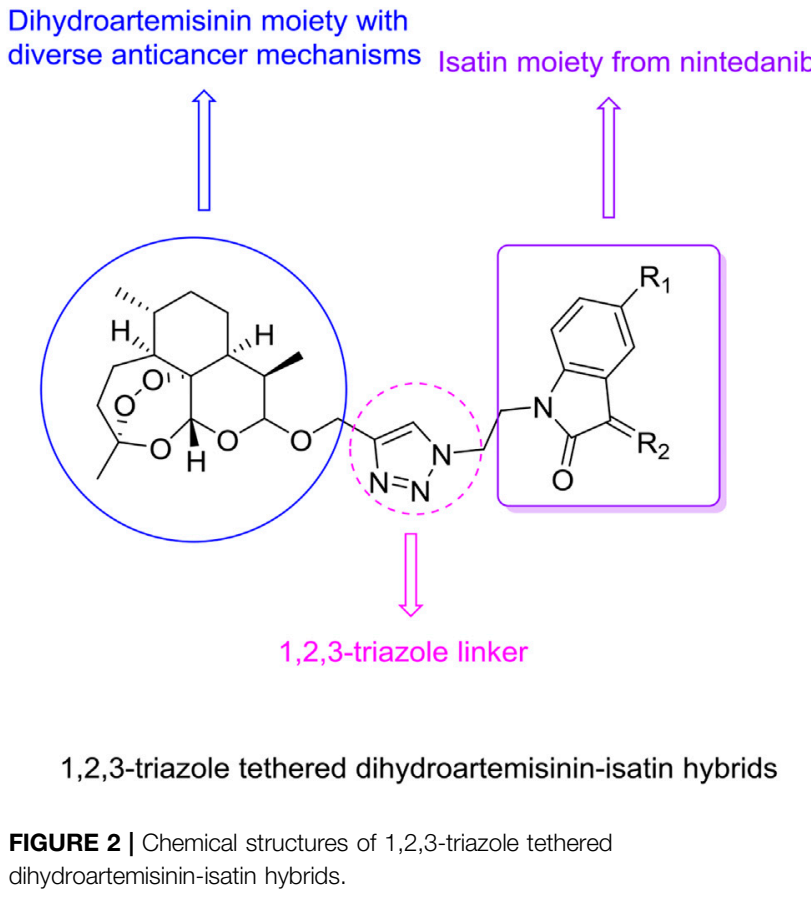

between the two functionalities (Sharma et al., 2015; Singh et al., 2016; Singh et al., 2017). Herein, we report the design, synthesis of various novel 1,2,3-triazole tethered dihydroartemisinin-isatin hybrids (Figure 2), and evaluation of their in vitro antiproliferative activity against A549, doxorubicin-resistant A549 (A549/DOX), cisplatinresistant A549 (A549/DDP) lung cancer cell lines, cytotoxicity towards mouse embryonic fibroblast cells $\mathrm{NIH} / 3 \mathrm{~T} 3$, liver stability and pharmacokinetic properties in this study. Our major goal is to optimize the anti-lung cancer potency of these hybrids, and preliminary studies on structure-activity relationships (SARs) are also taken to facilitate the further development of these hybrids.

\section{RESULTS AND DISCUSSION}

\section{Synthesis}

Firstly, we designed and synthesized the desired 1,2,3-triazole tethered dihydroartemisinin-isatin hybrids $8 \mathrm{a}-\mathrm{c}$ and $9 \mathrm{a}-\mathrm{k}$ following the synthetic routes shown in Scheme 1. Dihydroartemisinin 1 reacted with propargyl alcohol 2 in presence of boron trifluoride 


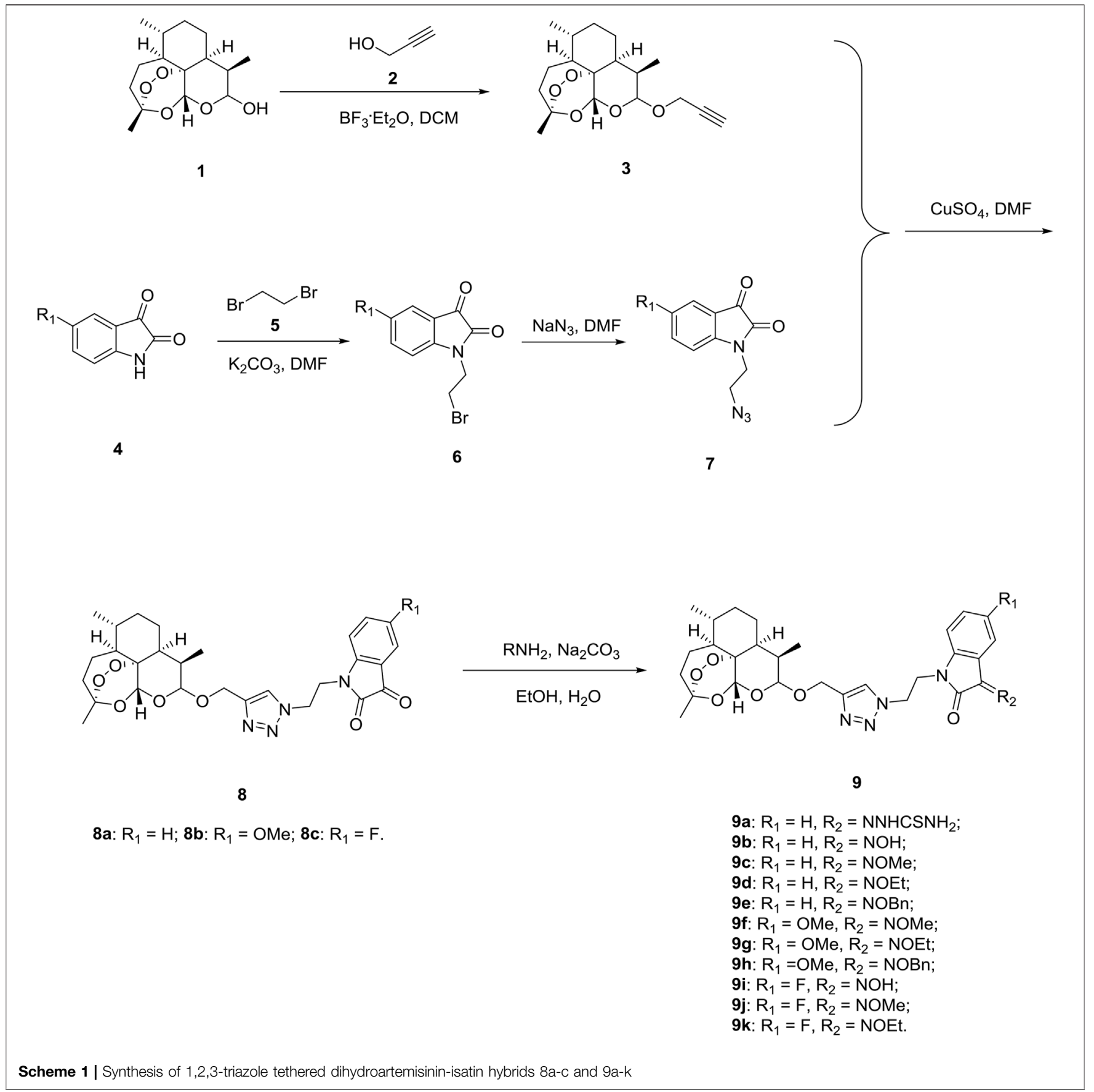

diethyl etherate $\left(\mathrm{BF}_{3} \cdot \mathrm{OEt}_{2}\right)$ and yielded alkynyl-containing dihydroartemisinin intermediate 3. Alkylation between isatins 4 and 1,2-dibromoethane 5) with potassium carbonate $\left(\mathrm{K}_{2} \mathrm{CO}_{3}\right)$ as base generated intermediates 6 , which were then reacted with sodium azide to give azido precursors 7 . The desired 1,2,3-triazole tethered dihydroartemisinin-isatin hybrids $8 \mathrm{a}-\mathrm{c}$ were obtained through $\mathrm{Cu}-$ promoted azide-alkyne cycloaddition reaction between intermediate 3 and azido precursors 7. Finally, 1,2,3-triazole tethered dihydroartemisinin-isatin hybrids $8 \mathrm{a}-\mathrm{c}$ reacted with amine hydrochlorides using sodium carbonate $\left(\mathrm{Na}_{2} \mathrm{CO}_{3}\right)$ as base and provided desired hybrids $9 \mathrm{a}-\mathrm{k}$.
All of the desired 1,2,3-triazole tethered dihydroartemisininisatin hybrids $8 \mathrm{a}-\mathrm{c}$ and $9 \mathrm{a}-\mathrm{k}$ were characterized by MS, ${ }^{1} \mathrm{H}$ NMR and ${ }^{13} \mathrm{C} \mathrm{NMR}$, and the corresponding analytical spectra were in the supplementary information section. The chemical structures and yields of desired hybrids were listed in Table $\mathbf{1}$.

\section{The In Vitro Antiproliferative Activity and Cytotoxicity}

The antiproliferative activity of 1,2,3-triazole tethered dihydroartemisinin-isatin hybrids $8 \mathrm{a}-\mathrm{c}$ and $9 \mathrm{a}-\mathrm{k}$ against A549, 
TABLE 1 | Chemical structures and yields of 1,2,3-triazole tethered dihydroartemisinin-isatin hybrids $8 \mathrm{a}-\mathrm{c}$ and $9 \mathrm{a}-\mathrm{k}$.

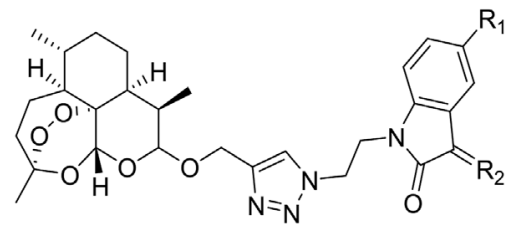

\begin{tabular}{llll}
\hline Compd & $\mathbf{R}_{\mathbf{1}}$ & \multicolumn{1}{c}{$\mathbf{R}_{\mathbf{2}}$} & Yield (\%) \\
\hline $\mathbf{8 a}$ & $\mathrm{H}$ & $\mathrm{O}$ & 37 \\
$\mathbf{8 b}$ & $\mathrm{OMe}$ & $\mathrm{O}$ & 28 \\
$\mathbf{8 c}$ & $\mathrm{F}$ & $\mathrm{O}$ & 33 \\
$\mathbf{9 a}$ & $\mathrm{H}$ & $\mathrm{NNHCSNH} \mathrm{H}_{2}$ & 49 \\
$\mathbf{9 b}$ & $\mathrm{H}$ & $\mathrm{NOH}$ & 83 \\
$\mathbf{9 c}$ & $\mathrm{H}$ & $\mathrm{NOMe}$ & 62 \\
$\mathbf{9 d}$ & $\mathrm{H}$ & $\mathrm{NOEt}$ & 57 \\
$\mathbf{9 e}$ & $\mathrm{H}$ & $\mathrm{NOBn}$ & 48 \\
$\mathbf{9 f}$ & $\mathrm{OMe}$ & $\mathrm{NOMe}$ & 59 \\
$\mathbf{9 g}$ & $\mathrm{OMe}$ & $\mathrm{NOBn}$ & 42 \\
$\mathbf{9 h}$ & $\mathrm{OMe}$ & $\mathrm{NOMe}$ & 41 \\
$\mathbf{9 i}$ & $\mathrm{F}$ & $\mathrm{NOMe}$ & 67 \\
$\mathbf{9 j}$ & $\mathrm{F}$ & $\mathrm{NOEt}$ & 52 \\
$\mathbf{9 k}$ & $\mathrm{F}$ & & 43 \\
\hline
\end{tabular}

multidrug-resistant A549/DOX and A549/DDP lung cancer cell lines as well as cytotoxicity towards mouse embryonic fibroblast cells NIH/3T3 were assessed by 3-(4,5-dimethylthiazol-2-yl)-2,5diphenyltetrazolium bromide (MTT) assay, and half maximal inhibitory concentration $\left(\mathrm{IC}_{50}\right.$ ) values were listed in Table 2.

From Table 2, it can be concluded that all of the desired 1,2,3triazole tethered dihydroartemisinin-isatin hybrids $8 \mathrm{a}-\mathrm{c}$ and $9 \mathrm{a}-\mathrm{k}$ were active against A549, multidrug-resistant A549/DOX and
A549/DDP lung cancer cell lines with $\mathrm{IC}_{50}$ values of 7.54-73.8 $\mu \mathrm{M}$. All hybrids were superior to the reference drugs artemisinin $\left(\mathrm{IC}_{50}:>100 \mu \mathrm{M}\right)$ and DHA $\left(\mathrm{IC}_{50}: 69.4-88.0 \mu \mathrm{M}\right)$ against both drug-sensitive and multidrug-resistant A549 lung cancer cell lines, and some of them also possessed higher activity than cisplatin $\left(\mathrm{IC}_{50}: 9.38-66.9 \mu \mathrm{M}\right)$. The SAR illustrated that introduction of hydroxime, alkyloxime, benzyloxime and thiosemicarbazide into $\mathrm{C}-3$ position of isatin moiety reduced the activity in comparison with the carbonyl analogs. Substituents on the $\mathrm{C}-5$ position of isatin motif had significant influence on the activity, and electron-withdrawing fluoro was beneficial for the activity, while electron-donating methoxy group led to great loss of activity.

All the desired hybrids $\left(\mathrm{IC}_{50}:>100 \mu \mathrm{M}\right)$ were non-cytotoxic towards mouse embryonic fibroblast cells NIH/3T3, and the selectivity index (SI: $\mathrm{IC}_{50 \text { (NIH/3T3) }} / \mathrm{IC}_{50 \text { (A549) }}$ ) values were $>1.3$, implying that these hybrids possessed acceptable specifity. The desired hybrids showed the same level activity against both drugsensitive and multidrug-resistant A549 lung cancer cell lines, and the drug resistance index (RI: $\mathrm{IC}_{50(\mathrm{MDR} A 549)} / \mathrm{IC}_{50(\mathrm{~A} 549)}$ ) values were $0.61-3.98$, revealing that these hybrids had low level cross resistance with doxorubicin and cisplatin.

Among them, the representative hybrids $8 \mathrm{a}, \mathrm{c} \quad\left(\mathrm{IC}_{50}\right.$ : 7.54-12.1 $\mu \mathrm{M})$ and $9 \mathrm{i}\left(\mathrm{IC}_{50}: 9.10-15.9 \mu \mathrm{M}\right)$ were highly potent against the three tested lung cancer cell lines, and the activity was comparable to that of cisplatin $\left(\mathrm{IC}_{50}: 7.54-15.9 \mu \mathrm{M}\right.$ vs 9.38-19.7 $\mu \mathrm{M}$ ) against A549 and A549/DOX, but 4.6-7.6 folds higher than that of cisplatin $\left(\mathrm{IC}_{50}: 8.77-14.3 \mu \mathrm{M}\right.$ vs $\left.66.9 \mu \mathrm{M}\right)$ against A549/DDP cells.

The metabolic stability of selected hybrids $8 \mathrm{a}, \mathrm{c}$ and $9 \mathrm{i}$ was assessed in mouse and human microsomes, and the results were

TABLE 2 | The antiproliferative activities, cytotoxicity, selectivity index and resistance index values of 1,2,3-triazole tethered dihydroartemisinin-isatin hybrids $\mathbf{8 a - c}$ and $\mathbf{9 a - k}$

\begin{tabular}{|c|c|c|c|c|c|c|c|}
\hline \multirow[t]{2}{*}{ Compd } & \multicolumn{4}{|c|}{$I C_{50}(\mu M)$} & \multirow[t]{2}{*}{$\mathbf{S I}^{\mathbf{a}}$} & \multicolumn{2}{|c|}{$\mathbf{R I}$} \\
\hline & A549 & A549/DOX ${ }^{b}$ & A549/DDP $^{c}$ & NIH/3T3 & & $R I 1^{d}$ & $\mathrm{R} 12^{\mathrm{e}}$ \\
\hline $8 a$ & 8.32 & 12.1 & 10.7 & $>100$ & $>12.0$ & 1.45 & 1.29 \\
\hline $8 b$ & 21.6 & 32.0 & 19.5 & $>100$ & $>4.6$ & 1.48 & 0.90 \\
\hline $8 c$ & 7.54 & 9.89 & 8.77 & $>100$ & >13.2 & 1.31 & 1.16 \\
\hline $9 a$ & 16.3 & 38.4 & 30.9 & $>100$ & $>6.1$ & 2.35 & 1.90 \\
\hline $9 b$ & 12.0 & 26.1 & 30.3 & $>100$ & $>8.3$ & 2.18 & 2.52 \\
\hline $9 c$ & 22.7 & 19.5 & 27.4 & $>100$ & $>4.4$ & 0.86 & 1.20 \\
\hline $9 d$ & 25.6 & 20.8 & 33.7 & $>100$ & $>3.9$ & 0.81 & 1.32 \\
\hline $9 e$ & 16.3 & 31.4 & 29.9 & $>100$ & $>6.1$ & 1.92 & 1.83 \\
\hline $9 f$ & 65.4 & 79.5 & 51.8 & $>100$ & $>1.5$ & 1.22 & 0.79 \\
\hline $9 g$ & 73.8 & 45.0 & 61.7 & $>100$ & $>1.3$ & 0.61 & 0.84 \\
\hline $9 \mathrm{~h}$ & 44.7 & 77.7 & 59.4 & $>100$ & $>2.2$ & 1.74 & 1.33 \\
\hline $9 i$ & 9.10 & 15.9 & 14.3 & $>100$ & $>11.0$ & 1.75 & 1.57 \\
\hline 9j & 9.61 & 13.0 & 38.2 & $>100$ & $>10.4$ & 1.35 & 3.98 \\
\hline $9 k$ & 15.8 & 31.1 & 28.7 & $>100$ & $>6.3$ & 1.97 & 1.82 \\
\hline Artemisinin & $>100$ & $>100$ & $>100$ & $>100$ & - & - & - \\
\hline $\mathrm{DH} \mathrm{A}^{\mathrm{f}}$ & 69.4 & 88.0 & 75.9 & $>100$ & $>1.4$ & 1.27 & 1.09 \\
\hline cisplatin & 9.38 & 19.7 & 66.9 & $>100$ & $>10.6$ & 2.10 & 7.13 \\
\hline
\end{tabular}

${ }^{b}$ Doxorubicin-resistant $A 549$ cells.

${ }^{c}$ Cisplatin-resistant A549 cells.

a Selectivity index: $1 C_{50(N / H / 3 T 3)} / C_{5 O(A 549)}$.

${ }^{d}$ Resistance index: $/ C_{50(A 549 / D O X)} / I_{50(A 549)}$.

${ }^{e}$ Resistance index: $/ C_{50(A 549 / D D P} / / C_{50(A 549)}$.

${ }^{f}$ Dihydroartemisinin. 
TABLE $\mathbf{3}$ | Stability of selected hybrids $\mathbf{8 a}, \mathbf{c}$ and $\mathbf{9 i}$ in mouse and human microsomes.

\begin{tabular}{lcc}
\hline \multirow{2}{*}{ Compd } & \multicolumn{3}{c}{ Liver microsomes [\%] } \\
\cline { 2 - 3 } & Mouse & Human \\
\hline $\mathbf{8 a}$ & 77 & 68 \\
$\mathbf{8 c}$ & 71 & 83 \\
$\mathbf{9 i}$ & 46 & 60
\end{tabular}

listed in Table 3. It can be concluded that hybrids $8 \mathrm{a}, \mathrm{c}$ (liver microsomes: $68-83 \%$ ) with carbonyl group at C-3 position of isatin moiety exhibited a superior microsomal stability than the hydroxime analog 9i (liver microsomes: 46 and 60\%).

The pharmacokinetic behavior of hybrids $8 \mathrm{a}, \mathrm{c}$ was determined in CD-1 mice model by single intravenous administration with dose of $30 \mathrm{mg} / \mathrm{kg}$. As summarized in Table 4, the pharmacokinetic properties of hybrids 8a,c as follows: the maximum plasma concentrations $\left(C_{\max }\right)$ of 6.4 and $12.5 \mu \mathrm{M}$, area under curve (AUC) of 883 and $654 \mathrm{ng} \mathrm{h} / \mathrm{ml}$, clearance rates $(\mathrm{Cl})$ of 2.31 and $3.16 \mathrm{~L} / \mathrm{h} / \mathrm{kg}$, half-lives $\left(\mathrm{t}_{1 / 2}\right)$ of 3.7 and $4.2 \mathrm{~h}$, peak time of $12 \mathrm{~min}$, and bioavailability of 35.6 and $27.5 \%$.

\section{CONCLUSION}

A series of 1,2,3-triazole tethered dihydroartemisinin-isatin hybrids $8 \mathrm{a}-\mathrm{c}$ and $9 \mathrm{a}-\mathrm{k}$ were designed, synthesized and assessed for their antiproliferative activity against A549, A549/DOX, and A549/DDP lung cancer cell lines in this study. All of these hybrids ( $\mathrm{IC}_{50}: 7.54-73.8 \mu \mathrm{M}$ ) were more potent than the parent drug dihydroartemisinin $\left(\mathrm{IC}_{50}: 69.4-88.0 \mu \mathrm{M}\right)$ against the tested cancer cell lines. In addition, all hybrids $\left(\mathrm{IC}_{50}:>100 \mu \mathrm{M}\right)$ displayed non-cytotoxic towards NIH/3T3 cells. Among them, hybrids $8 \mathrm{a}, \mathrm{c}\left(\mathrm{IC}_{50}: 7.54-12.1 \mu \mathrm{M}\right)$ and $9 \mathrm{i}\left(\mathrm{IC}_{50}: 9.10-15.9 \mu \mathrm{M}\right)$ were not inferior to cisplatin $\left(\mathrm{IC}_{50}: 9.38-66.9 \mu \mathrm{M}\right)$ against the three cancer cell lines. Moreover, hybrids $8 \mathrm{a}, \mathrm{c}$ possessed excellent stability and good pharmacokinetic properties, demonstrating their potential as novel anti-lung cancer chemotherapeutic candidates. Accordingly, hybrids $8 \mathrm{a}, \mathrm{c}$ merits further preclinical evaluations.

\section{EXPERIMENTAL SECTION}

\section{Materials}

${ }^{1} \mathrm{H}$ NMR and ${ }^{13} \mathrm{C}$ NMR spectra were determined on a Varian Mercury-400 spectrometer in $\mathrm{CDCl}^{3} \mathrm{fn} 3$ using tetramethylsilane (TMS) as an internal standard. Electrospray ionization (ESI) mass spectra were obtained on a MDSSCIEXQ-Tap mass spectrometer. Unless otherwise noted, the reagents were obtained from commercial supplier and were used without further purification. A549, A549/DOX, and A549/DDP lung cancer cell lines were purchased from the American Type Culture Collection (ATCC) and preserved by Center for Experimental Nuclear Medicine of Shandong University.
TABLE 4 | Pharmacokinetic properties of hybrids $\mathbf{8 a , c}$ in mice.

\begin{tabular}{lcc}
\hline \multirow{2}{*}{ Parameter } & \multicolumn{2}{c}{ Compd. } \\
\cline { 2 - 3 } & $\mathbf{8 a}$ & $\mathbf{8 c}$ \\
\hline$C_{\max }(\mu \mathrm{M})$ & 6.4 & 12.5 \\
$\mathrm{AUC}(\mathrm{ng} \cdot \mathrm{h} / \mathrm{ml})$ & 883 & 654 \\
$t_{1 / 2}(\mathrm{~h})$ & 3.7 & 4.2 \\
$t_{\max }(\min )$ & 12 & 12 \\
$\mathrm{Cl}(\mathrm{L} / \mathrm{h} / \mathrm{kg})$ & 2.31 & 3.16 \\
$F(\%)$ & 35.6 & 27.5
\end{tabular}

\section{Synthesis}

To a mixture of dihydroartemisinin $1(100 \mathrm{mmol})$ and propargyl alcohol $2(120 \mathrm{mmol})$ in DCM $(500 \mathrm{ml})$ was added boron trifluoride diethyl etherate $\left(\mathrm{BF}_{3} \cdot \mathrm{OEt}_{2}, 20 \mathrm{ml}\right)$ at $0^{\circ} \mathrm{C}$, and the mixture was stirred at room temperatire overnight. Sat. $\mathrm{Na}_{2} \mathrm{CO}_{3}$ $(500 \mathrm{ml})$ was added to the mixture, and then the organic layer was separated. The organic layer was washed with $\mathrm{H}_{2} \mathrm{O}(500 \mathrm{ml})$ and brine $(500 \mathrm{ml})$ in sequence, dried over anhydrous $\mathrm{Na}_{2} \mathrm{SO}_{4}$, filtered, and concentrated under reduced pressure to give crude alkynyl-containing dihydroartemisinin intermediate 3 .

To a solution of isatins $4(100 \mathrm{mmol})$ in DMF $(100 \mathrm{ml})$, potassium carbonate $\left(\mathrm{K}_{2} \mathrm{CO}_{3}, 200 \mathrm{mmol}\right)$ was added. The mixture was stirred at room temperature for $1 \mathrm{~h}$, and then 1,2dibromoethane $(5,150 \mathrm{mmol})$ was added. The mixture was stirred overnight at room temperature, and then filtered. The mixture was concentrated under reduced pressure and the residue was purified by silica gel chromatography eluted with PE to PE: $\mathrm{EA}=2: 1$ to provide intermediates 6 .

A mixture of intermediates $6(10 \mathrm{mmol})$ and $\mathrm{NaN}_{3}(15 \mathrm{mmol})$ in DMF (30 mmol) was stirred at $50^{\circ} \mathrm{C}$ for $12 \mathrm{~h}$, and then cooled to room temperature. $\mathrm{H}_{2} \mathrm{O}(100 \mathrm{ml})$ was added to the mixture, and the mixture was extracted with $\mathrm{DCM}(100 \mathrm{ml} \times 3)$. The combined organic layers were washed with $\mathrm{H}_{2} \mathrm{O}(500 \mathrm{ml})$ and brine $(500 \mathrm{ml})$ in sequence, dried over anhydrous $\mathrm{Na}_{2} \mathrm{SO}_{4}$, filtered, and concentrated under reduced pressure to give crude azido precursors 7 .

The mixture of intermediates $6(3 \mathrm{mmol})$, precursors 7 $(3 \mathrm{mmol})$ and $\mathrm{CuSO}_{4}(1 \mathrm{mmol})$ in DMF $(10 \mathrm{mmol})$ was stirred at $60^{\circ} \mathrm{C}$ for $8 \mathrm{~h}$ under $\mathrm{N}_{2}$ atmosphere, and then cooled to room temperature. After filtration, the filtrate was concentrated under reduced pressure. The residue was purified by silica gel chromatography eluted with $\mathrm{PE}$ to $\mathrm{PE}: \mathrm{EA}=1: 2$ to generate 1,2,3-triazole tethered dihydroartemisinin-isatin hybrids $8 \mathrm{a}-\mathrm{c}$.

To a solution of hybrids $8 \mathrm{a}-\mathrm{c}(1 \mathrm{mmol})$ and amine hydrochlorides $(1.5 \mathrm{mmol})$ in a mixture of $\mathrm{EtOH}(10 \mathrm{ml})$ and $\mathrm{H}_{2} \mathrm{O}(10 \mathrm{ml}), \mathrm{Na}_{2} \mathrm{CO}_{3}(2 \mathrm{mmol})$ was added. The mixture was stirred at $60^{\circ} \mathrm{C}$ for $12 \mathrm{~h}$, and then cooled to room temperature. The mixture was extracted with DCM $(20 \mathrm{ml} \times 3)$. The combined organic layers were washed with $\mathrm{H}_{2} \mathrm{O}(30 \mathrm{ml})$ and brine $(30 \mathrm{ml})$ in sequence, dried over anhydrous $\mathrm{Na}_{2} \mathrm{SO}_{4}$, filtered, and concentrated under reduced pressure. The residue was purified by silica gel chromatography eluted with PE to PE:EA = 1:2 to give 1,2,3-triazole tethered dihydroartemisinin-isatin hybrids $9 \mathrm{a}-\mathrm{k}$. 


\section{Characterization}

1-(2-(4- $((((3 R, 5 \mathrm{a} S, 6 R, 8 \mathrm{a} S, 9 R, 12 R, 12 \mathrm{a} R)-3,6,9-$

trimethyldecahydro-12H-3,12-epoxy (Willis et al., 2019; Sławiński et al., 2020)dioxepino [4,3-i]isochromen-10-yl)oxy) methyl)-1H-1,2,3-triazol-1-yl)ethyl)indoline-2,3-dione (8a).

Red solid, yield: $37 \% .{ }^{1} \mathrm{H}$ NMR (400 MHz, $\left.\mathrm{CDCl}_{3}\right)$ ઈ 0.75-0.92 $(\mathrm{m}, 7 \mathrm{H}), 1.11-1.14(\mathrm{~m}, 1 \mathrm{H}), 1.31-1.35(\mathrm{~m}, 1 \mathrm{H}), 1.48-1.55(\mathrm{~m}$, $5 \mathrm{H}), 1.60-1.63(\mathrm{~m}, 1 \mathrm{H}), 1.68-1.71(\mathrm{~m}, 2 \mathrm{H}), 1.76-1.80(\mathrm{~m}, 2 \mathrm{H})$, 1.99-2.06 (m, 1H), 2.33-2.36 (m, 1H), $3.50(\mathrm{~d}, J=4.0 \mathrm{~Hz}, 1 \mathrm{H})$, $4.18(\mathrm{t}, J=4.0 \mathrm{~Hz}, 2 \mathrm{H}), 4.46(\mathrm{~d}, J=8.0 \mathrm{~Hz}, 1 \mathrm{H}), 4.69(\mathrm{t}, J=4.0 \mathrm{~Hz}$, $2 \mathrm{H}), 4.74(\mathrm{dd}, J=8.0,4.0 \mathrm{~Hz}, 1 \mathrm{H}), 5.18(\mathrm{~s}, 1 \mathrm{H}), 6.52(\mathrm{~d}, J=4.0 \mathrm{~Hz}$, $1 \mathrm{H}), 7.00(\mathrm{~d}, J=4.0 \mathrm{~Hz}, 1 \mathrm{H}), 7.42(\mathrm{t}, J=4.0 \mathrm{~Hz}, 1 \mathrm{H}), 7.50(\mathrm{~d}, J=$ $4.0 \mathrm{~Hz}, 1 \mathrm{H}) .{ }^{13} \mathrm{C} \mathrm{NMR}\left(100 \mathrm{MHz}, \mathrm{CDCl}_{3}\right) \delta 182.36,158.57$, $150.05,145.72,138.69,125.61,124.20,123.54,117.38,109.63$, $108.02,99.51,93.67,84.12,69.56,61.51,47.70,42.47,40.73,40.59$, $34.83,34.67,30.33,30.23,25.00,21.00,18.82,12.31$. HRMS-ESI: $\mathrm{m} / \mathrm{z}$ Calcd for $\mathrm{C}_{28} \mathrm{H}_{34} \mathrm{~N}_{4} \mathrm{O}_{7} \mathrm{Na}[\mathrm{M}+\mathrm{Na}]^{+}$: 561.2320; Found: 561.2314 .

5-methoxy-1-(2-(4-((( $3 R, 5 \mathrm{a} S, 6 R, 8 \mathrm{a} S, 9 R, 12 R, 12 \mathrm{a} R)-3,6,9-$ trimethyldecahydro-12H-3,12-epoxy (Willis et al., 2019; Sławiński et al., 2020)dioxepino [4,3-i]isochromen-10-yl)oxy) methyl)-1H-1,2,3-triazol-1-yl)ethyl)indoline-2,3-dione (8b).

Red solid, yield: $28 \% .{ }^{1} \mathrm{H}$ NMR (400 MHz, $\left.\mathrm{CDCl}_{3}\right) \delta 0.75-0.92$ $(\mathrm{m}, 7 \mathrm{H}), 1.13-1.17(\mathrm{~m}, 1 \mathrm{H}), 1.30-1.35(\mathrm{~m}, 1 \mathrm{H}), 1.48-1.56(\mathrm{~m}$, $5 \mathrm{H}), 1.60-1.63(\mathrm{~m}, 1 \mathrm{H}), 1.68-1.70(\mathrm{~m}, 2 \mathrm{H}), 1.76-1.81(\mathrm{~m}, 2 \mathrm{H})$, $1.98(\mathrm{~d}, J=8.0 \mathrm{~Hz}, 1 \mathrm{H}), 2.34-2.36(\mathrm{~m}, 1 \mathrm{H}), 3.50(\mathrm{~d}, J=4.0 \mathrm{~Hz}$, $1 \mathrm{H}), 3.70(\mathrm{~s}, 3 \mathrm{H}), 4.15(\mathrm{t}, J=4.0 \mathrm{~Hz}, 2 \mathrm{H}), 4.48(\mathrm{~d}, J=12.0 \mathrm{~Hz}, 1 \mathrm{H})$, $4.62(\mathrm{t}, J=4.0 \mathrm{~Hz}, 2 \mathrm{H}), 4.70(\mathrm{dd}, J=2.0 \mathrm{~Hz}, 1 \mathrm{H}), 4.74(\mathrm{~d}, J=$ $4.0 \mathrm{~Hz}, 1 \mathrm{H}), 5.18(\mathrm{~s}, 1 \mathrm{H}), 6.44(\mathrm{~d}, J=4.0 \mathrm{~Hz}, 1 \mathrm{H}), 6.94(\mathrm{dd}, J=4.0$, $2.0 \mathrm{~Hz}, 1 \mathrm{H}), 7.02(\mathrm{~d}, J=4.0 \mathrm{~Hz}, 1 \mathrm{H}), 7.20(\mathrm{~s}, 1 \mathrm{H}), 7.93(\mathrm{~s}, 1 \mathrm{H}) .{ }^{13} \mathrm{C}$ NMR $\left(100 \mathrm{MHz}, \mathrm{CDCl}_{3}\right) \delta 182.72,158.70,156.70,145.72,143.88$, $135.79,125.52,124.80,123.53,117.84,110.68,109.80,108.02$, $99.49,93.70,84.12,69.58,61.52,55.93,47.78,42.47,40.78,40.61$, $34.83,34.68,30.33,30.25,24.99,20.99,18.82,12.27$. HRMS-ESI: $\mathrm{m} / \mathrm{z}$ Calcd for $\mathrm{C}_{29} \mathrm{H}_{36} \mathrm{~N}_{4} \mathrm{O}_{8} \mathrm{Na}[\mathrm{M}+\mathrm{Na}]^{+}$: 591.2426; Found: 591.2410 .

5-fluoro-1-(2-(4-((( $3 R, 5 \mathrm{a} S, 6 R, 8 \mathrm{a} S, 9 R, 12 R, 12 \mathrm{a} R)-3,6,9$ -

trimethyldecahydro-12H-3,12-epoxy (Willis et al., 2019; Sławiński et al., 2020)dioxepino [4,3-i]isochromen-10-yl)oxy) methyl)-1H-1,2,3-triazol-1-yl)ethyl)indoline-2,3-dione (8c).

Red solid, yield: $33 \% .{ }^{1} \mathrm{H} \mathrm{NMR}\left(400 \mathrm{MHz}, \mathrm{CDCl}_{3}\right) \delta 0.76-0.93$ $(\mathrm{m}, 7 \mathrm{H}), 1.13-1.14(\mathrm{~m}, 1 \mathrm{H}), 1.33-1.35(\mathrm{~m}, 1 \mathrm{H}), 1.48-1.56(\mathrm{~m}$, $5 \mathrm{H}), 1.60-1.63(\mathrm{~m}, 1 \mathrm{H}), 1.68-1.71(\mathrm{~m}, 3 \mathrm{H}), 1.76-1.82(\mathrm{~m}, 2 \mathrm{H})$, $1.98-2.06(\mathrm{~m}, 1 \mathrm{H}), 2.34-2.37(\mathrm{~m}, 1 \mathrm{H}), 3.50(\mathrm{~s}, 1 \mathrm{H}), 4.20(\mathrm{t}, J=$ $4.0 \mathrm{~Hz}, 2 \mathrm{H}), 4.46(\mathrm{~d}, J=8.0 \mathrm{~Hz}, 1 \mathrm{H}), 4.63(\mathrm{t}, J=4.0 \mathrm{~Hz}, 2 \mathrm{H}), 4.80$ $(\mathrm{dd}, J=8.0,4.0 \mathrm{~Hz}, 1 \mathrm{H}), 5.18(\mathrm{~s}, 1 \mathrm{H}), 6.50(\mathrm{dd}, J=8.0,4.0 \mathrm{~Hz}, 1 \mathrm{H})$, $7.12(\mathrm{td}, J=8.0,2.0 \mathrm{~Hz}, 1 \mathrm{H}), 7.20(\mathrm{dd}, J=4.0,2.0 \mathrm{~Hz}, 1 \mathrm{H}), 7.44(\mathrm{~s}$, $1 \mathrm{H}) .{ }^{13} \mathrm{C} \mathrm{NMR}\left(100 \mathrm{MHz}, \mathrm{CDCl}_{3}\right) \delta 181.80,160.19(\mathrm{~J}=$ $205.00 \mathrm{~Hz}), 158.35,146.13,145.79,127.10,124.94,123.63$, $118.01,117.97,112.65,112.49,111.03,110.98,108.03,99.47$, $93.75,84.08,69.56,61.53,47.74,42.42,40.88,40.57,34.84$, $34.65,30.32,30.24,24.99,20.97,18.81,12.22$. HRMS-ESI: $\mathrm{m} / \mathrm{z}$ Calcd for $\mathrm{C}_{28} \mathrm{H}_{33} \mathrm{FN}_{4} \mathrm{O}_{7} \mathrm{Na}[\mathrm{M}+\mathrm{Na}]^{+}:$579.2226; Found: 579.2233 .

2-(2-oxo-1-(2-(4- $((((3 R, 5 \mathrm{a} S, 6 R, 8 \mathrm{a} S, 9 R, 12 R, 12 \mathrm{a} R)-3,6,9-$

trimethyldecahydro-12H-3,12-epoxy (Willis et al., 2019; Sławiński et al., 2020)dioxepino [4,3-i]isochromen-10-yl)oxy)
methyl)-1H-1,2,3-triazol-1-yl)ethyl)indolin-3-ylidene)

hydrazine-1-carbothioamide (9a).

Yellow solid, yield: $49 \%$. ${ }^{1} \mathrm{H}$ NMR $\left(400 \mathrm{MHz}, \mathrm{CDCl}_{3}\right) \delta$ 0.75-0.92 (m, 7H), 1.12-1.16 (m, 1H), 1.31-1.36 (m, $1 \mathrm{H})$, $1.48-1.56(\mathrm{~m}, 5 \mathrm{H}), 1.60-1.62(\mathrm{~m}, 1 \mathrm{H}), 1.69-1.72(\mathrm{~m}, 2 \mathrm{H})$, $1.72-1.81(\mathrm{~m}, 2 \mathrm{H}), 2.05-2.06(\mathrm{~m}, 1 \mathrm{H}), 2.33-2.36(\mathrm{~m}, 1 \mathrm{H}), 3.50$ $(\mathrm{d}, J=2.0 \mathrm{~Hz}, 1 \mathrm{H}), 4.20(\mathrm{td}, J=4.0,2.0 \mathrm{~Hz}, 2 \mathrm{H}), 4.46(\mathrm{~d}, J=$ $8.0 \mathrm{~Hz}, 1 \mathrm{H}), 4.61-4.65(\mathrm{~m}, 2 \mathrm{H}), 4.67(\mathrm{~d}, J=2.0 \mathrm{~Hz}, 1 \mathrm{H}), 4.72(\mathrm{~d}$, $J=8.0,4.0 \mathrm{~Hz}, 1 \mathrm{H}), 5.18(\mathrm{~s}, 1 \mathrm{H}), 6.52(\mathrm{~d}, J=4.0 \mathrm{~Hz}, 1 \mathrm{H}), 6.75(\mathrm{~s}$, $1 \mathrm{H}), 7.00(\mathrm{t}, J=4.0 \mathrm{~Hz}, 1 \mathrm{H}), 7.22(\mathrm{t}, J=4.0 \mathrm{~Hz}, 1 \mathrm{H}), 7.38(\mathrm{~s}, 1 \mathrm{H})$, $7.46(\mathrm{~d}, J=4.0 \mathrm{~Hz}, 1 \mathrm{H}), 7.49(\mathrm{~s}, 1 \mathrm{H}), 12.60(\mathrm{~s}, 1 \mathrm{H}) .{ }^{13} \mathrm{C} \mathrm{NMR}$ $\left(100 \mathrm{MHz}, \mathrm{CDCl}_{3}\right) \delta 179.92,161.24,145.64,142.37,131.76$, $131.15,123.69,123.37,121.01,119.06,108.84,108.02,99.32$, $93.71,84.13,69.58,61.40,47.72,42.45,40.59,40.36,34.83$, $34.70,30.34,30.25,25.01,21.01,18.84,12.31$. HRMS-ESI: $\mathrm{m} / \mathrm{z}$ Calcd for $\mathrm{C}_{29} \mathrm{H}_{37} \mathrm{~N}_{7} \mathrm{O}_{6} \mathrm{SNa}[\mathrm{M}+\mathrm{Na}]^{+}$: 634.2419; Found: 634.2407.

3-(hydroxyimino)-1-(2-(4-((((3R,5aS,6R,8aS,9R,12R,12aR)3,6,9-trimethyldecahydro-12H-3,12-epoxy (Willis et al., 2019; Sławiński et al., 2020)dioxepino [4,3-i]isochromen-10-yl)oxy) methyl)-1H-1,2,3-triazol-1-yl)ethyl)indolin-2-one (9b).

Yellow solid, yield: $83 \% .{ }^{1} \mathrm{H}$ NMR $\left(400 \mathrm{MHz}, \mathrm{CD}_{3} \mathrm{OD}\right) \delta$ 0.71-0.90 (m, 7H), 1.07-1.20 (m, 2H), 1.36-1.41 (m, 4H), $1.49-1.56(\mathrm{~m}, 3 \mathrm{H}), 1.67-1.70(\mathrm{~m}, 2 \mathrm{H}), 1.74-1.78(\mathrm{~m}, 1 \mathrm{H})$, $2.26-2.29(\mathrm{~m}, 1 \mathrm{H}), 3.40(\mathrm{~d}, J=2.0 \mathrm{~Hz}, 1 \mathrm{H}), 4.16(\mathrm{t}, J=4.0 \mathrm{~Hz}$, $1 \mathrm{H}), 4.40(\mathrm{~d}, J=8.0 \mathrm{~Hz}, 1 \mathrm{H}), 4.57-4.68(\mathrm{~m}, 4 \mathrm{H}), 5.15(\mathrm{~s}, 1 \mathrm{H}), 6.66$ $(\mathrm{d}, J=4.0 \mathrm{~Hz}, 1 \mathrm{H}), 6.96(\mathrm{t}, J=8.0 \mathrm{~Hz}, 1 \mathrm{H}), 7.22(\mathrm{~d}, J=8.0 \mathrm{~Hz}, 1 \mathrm{H})$, $7.78(\mathrm{~s}, 1 \mathrm{H}), 7.92(\mathrm{~d}, J=4.0 \mathrm{~Hz}, 1 \mathrm{H}) .{ }^{13} \mathrm{C}$ NMR $(100 \mathrm{MHz}$, $\left.\mathrm{CD}_{3} \mathrm{OD}\right) \delta 164.80,144.81,143.34,142.37,131.67,127.21,124.47$, $123.04,115.55,108.17,107.99,98.98,93.50,83.80,68.59,60.31$, 42.08, 40.59, 39.92, 34.53, 34.49, 30.20, 30.08, 24.81, 20.09, 17.92, 11.34. HRMS-ESI: $\mathrm{m} / \mathrm{z}$ Calcd for $\mathrm{C}_{30} \mathrm{H}_{39} \mathrm{FN}_{5} \mathrm{O}_{7} \mathrm{Na}[\mathrm{M}+\mathrm{Na}]^{+}$: 576.2429; Found: 576.2440.

3-(methoxyimino)-1-(2-(4-(((3R,5aS,6R,8aS,9R,12R,12aR)3,6,9-trimethyldecahydro-12H-3,12-epoxy (Willis et al., 2019; Sławiński et al., 2020)dioxepino [4,3-i]isochromen-10-yl)oxy) methyl)-1H-1,2,3-triazol-1-yl)ethyl)indolin-2-one (9c).

Yellow solid, yield: $62 \% .{ }^{1} \mathrm{H}$ NMR $\left(400 \mathrm{MHz}, \mathrm{CDCl}_{3}\right) \delta$ 0.73-0.91 (m, 7H), 1.12-1.16 (m, 1H), 1.29-1.34 (m, 1H), $1.48-1.56(\mathrm{~m}, 5 \mathrm{H}), 1.60-1.63(\mathrm{~m}, 1 \mathrm{H}), 1.67-1.70(\mathrm{~m}, 2 \mathrm{H})$, $1.76-1.80(\mathrm{~m}, 2 \mathrm{H}), 1.98(\mathrm{~d}, J=4.0 \mathrm{~Hz}, 1 \mathrm{H}), 2.32-2.34(\mathrm{~m}, 1 \mathrm{H})$, $3.50(\mathrm{~d}, J=4.0 \mathrm{~Hz} 1 \mathrm{H}), 4.14-4.23(\mathrm{~m}, 5 \mathrm{H}), 4.44(\mathrm{~d}, J=8.0 \mathrm{~Hz}, 1 \mathrm{H})$, $4.58-4.63(\mathrm{~m}, 3 \mathrm{H}), 4.70(\mathrm{~d}, J=12.0 \mathrm{~Hz}, 1 \mathrm{H}), 5.17(\mathrm{~s}, 1 \mathrm{H}), 6.42(\mathrm{~d}, J=$ $8.0 \mathrm{~Hz}, 1 \mathrm{H}), 6.94(\mathrm{t}, J=8.0 \mathrm{~Hz}, 1 \mathrm{H}), 7.20(\mathrm{t}, J=4.0 \mathrm{~Hz}, 1 \mathrm{H}), 7.32(\mathrm{~s}$, $1 \mathrm{H}), 7.84(\mathrm{~d}, J=4.0 \mathrm{~Hz}, 1 \mathrm{H}) .{ }^{13} \mathrm{C} \mathrm{NMR}\left(100 \mathrm{MHz}, \mathrm{CDCl}_{3}\right) \delta 163.84$, $145.53,143.00,142.87,132.69,128.00,123.43,123.39,121.07$, $115.47,108.01,99.47,93.57,84.16,69.58,64.96,61.43,47.94$, $42.54,40.62,40.56,40.53,34.80,34.69,30.33,30.20,24.99,21.02$, 18.84, 12.34. HRMS-ESI: $\mathrm{m} / \mathrm{z}$ Calcd for $\mathrm{C}_{29} \mathrm{H}_{37} \mathrm{~N}_{5} \mathrm{O}_{7} \mathrm{Na}[\mathrm{M}+\mathrm{Na}]^{+}$: 590.2586; Found: 590.2573.

3-(ethoxyimino)-1-(2-(4- $(((3 R, 5 \mathrm{a} S, 6 R, 8 \mathrm{a} S, 9 R, 12 R, 12 \mathrm{a} R)$ 3,6,9-trimethyldecahydro-12H-3,12-epoxy (Willis et al., 2019; Sławiński et al., 2020)dioxepino [4,3-i]isochromen-10-yl)oxy) methyl)-1H-1,2,3-triazol-1-yl)ethyl)indolin-2-one (9d).

Yellow solid, yield: $57 \%$. ${ }^{1} \mathrm{H}$ NMR $\left(400 \mathrm{MHz}, \mathrm{CDCl}_{3}\right) \delta$ 0.73-0.91 (m, 7H), 1.13-1.16 (m, 1H), 1.30-1.34 (m, 1H), 1.39 $(\mathrm{t}, J=4.0 \mathrm{~Hz}, 3 \mathrm{H}), 1.48-1.56(\mathrm{~m}, 5 \mathrm{H}), 1.60-1.63(\mathrm{~m}, 2 \mathrm{H})$, 
$1.67-1.70(\mathrm{~m}, 1 \mathrm{H}), 1.76-1.80(\mathrm{~m}, 2 \mathrm{H}), 1.94(\mathrm{~d}, J=4.0 \mathrm{~Hz}, 1 \mathrm{H})$, 2.32-2.34 (m, 1H), $3.50(\mathrm{~d}, J=4.0 \mathrm{~Hz} 1 \mathrm{H}), 4.20(\mathrm{q}, J=4.0 \mathrm{~Hz}$, $2 \mathrm{H}), 4.44(\mathrm{~d}, J=8.0 \mathrm{~Hz}, 1 \mathrm{H}), 4.50(\mathrm{q}, J=4.0 \mathrm{~Hz}, 2 \mathrm{H}), 4.60-4.63$ $(\mathrm{m}, 3 \mathrm{H}), 4.72(\mathrm{~d}, J=8.0 \mathrm{~Hz}, 1 \mathrm{H}), 5.17(\mathrm{~s}, 1 \mathrm{H}), 6.42(\mathrm{~d}, J=4.0 \mathrm{~Hz}$, $1 \mathrm{H}), 6.95(\mathrm{t}, J=4.0 \mathrm{~Hz}, 1 \mathrm{H}), 7.18(\mathrm{t}, J=4.0 \mathrm{~Hz}, 1 \mathrm{H}), 7.31(\mathrm{~s}, 1 \mathrm{H})$, $7.86(\mathrm{~d}, J=4.0 \mathrm{~Hz}, 1 \mathrm{H}) .{ }^{13} \mathrm{C} \mathrm{NMR}\left(100 \mathrm{MHz}, \mathrm{CDCl}_{3}\right) \delta 163.99$, $145.54,142.83,142.76,132.51,127.90,123.42,123.35,115.58$, $108.02,107.94,99.48,93.57,84.17,73.31,69.60,61.44,48.00$, $42.55,40.63,40.56,34.80,34.70,30.23,30.20,24.99,21.02,18.83$, 14.70, 12.36. HRMS-ESI: $\mathrm{m} / \mathrm{z}$ Calcd for $\mathrm{C}_{30} \mathrm{H}_{39} \mathrm{~N}_{5} \mathrm{O}_{7} \mathrm{Na}[\mathrm{M}+$ $\mathrm{Na}]^{+}:$604.2742; Found: 604.2747.

3-((benzyloxy)imino)-1-(2-(4-

((((3R,5aS,6R,8aS,9R,12R,12aR)-3,6,9-trimethyldecahydro- $12 H$ 3,12-epoxy (Willis et al., 2019; Sławiński et al., 2020)dioxepino [4,3-i] isochromen-10-yl)oxy)methyl)-1H-1,2,3-triazol-1-yl) ethyl)indolin-2-one (9e).

Yellow solid, yield: $48 \%$. ${ }^{1} \mathrm{H}$ NMR $\left(400 \mathrm{MHz}, \mathrm{CDCl}_{3}\right) \delta$ $0.72-0.88(\mathrm{~m}, 7 \mathrm{H}), 1.12-1.14(\mathrm{~m}, 1 \mathrm{H}), 1.29-1.32(\mathrm{~m}, 1 \mathrm{H})$, $1.48-1.56(\mathrm{~m}, 5 \mathrm{H}), 1.59-1.62(\mathrm{~m}, 2 \mathrm{H}), 1.66-1.70(\mathrm{~m}, 2 \mathrm{H})$, 1.75-1.79 (m, 2H), 2.33-2.34 (m, 1H), $3.50(\mathrm{~s}, 1 \mathrm{H}), 4.18(\mathrm{q}$, $J=4.0 \mathrm{~Hz}, 2 \mathrm{H}), 4.44(\mathrm{~d}, J=12.0 \mathrm{~Hz}, 1 \mathrm{H}), 4.63(\mathrm{td}, J=4.0,2.0 \mathrm{~Hz}$, $2 \mathrm{H}), 4.72(\mathrm{~d}, J=8.0 \mathrm{~Hz}, 1 \mathrm{H}), 5.17(\mathrm{~s}, 1 \mathrm{H}), 5.46(\mathrm{~s}, 1 \mathrm{H}), 6.42(\mathrm{~d}, J=$ $8.0 \mathrm{~Hz}, 1 \mathrm{H}), 6.90(\mathrm{t}, J=8.0 \mathrm{~Hz}, 1 \mathrm{H}), 7.16(\mathrm{t}, J=8.0 \mathrm{~Hz}, 1 \mathrm{H})$, 7.30-7.39 (m, 6H), $7.82(\mathrm{~s}, 1 \mathrm{H}) .{ }^{13} \mathrm{C} \mathrm{NMR}\left(100 \mathrm{MHz}, \mathrm{CDCl}_{3}\right) \delta$ $163.89,145.55,143.36,142.88,135.96,132.74,128.68,128.62$, $128.54,128.15,123.46,124.43,115.53,108.02,107.99,99.50$, $93.59,84.17,79.66,69.61,61.45,47.98,42.55,40.62,40.58$, $34.80,34.70,30.33,30.21,24.99,21.02,18.83,12.35$. HRMSESI: $\mathrm{m} / \mathrm{z}$ Calcd for $\mathrm{C}_{35} \mathrm{H}_{41} \mathrm{~N}_{5} \mathrm{O}_{7} \mathrm{Na}[\mathrm{M}+\mathrm{Na}]^{+}$: 666.2899; Found: 666.2904 .

5-methoxy-3-(methoxyimino)-1-(2-(4-

$((((3 R, 5 \mathrm{aS}, 6 R, 8 \mathrm{aS}, 9 R, 12 R, 12 \mathrm{a} R)-3,6,9$-trimethyldecahydro- $12 \mathrm{H}$ 3,12-epoxy (Willis et al., 2019; Sławiński et al., 2020)dioxepino [4,3-i] isochromen-10-yl)oxy)methyl)-1H-1,2,3-triazol-1-yl) ethyl)indolin-2-one (9f).

Yellow solid, yield: $59 \%$. ${ }^{1} \mathrm{H}$ NMR $\left(400 \mathrm{MHz}, \mathrm{CDCl}_{3}\right) \delta$ 0.74-0.91 (m, 7H), 1.11-1.16 (m, 1H), 1.29-1.34 (m, 1H), $1.48-1.55(\mathrm{~m}, 5 \mathrm{H}), 1.60-1.63(\mathrm{~m}, 1 \mathrm{H}), 1.67-1.70(\mathrm{~m}, 1 \mathrm{H})$, $1.76-1.80(\mathrm{~m}, 2 \mathrm{H}), 1.98(\mathrm{~d}, J=4.0 \mathrm{~Hz}, 1 \mathrm{H}), 2.30-2.35(\mathrm{~m}$, $1 \mathrm{H}), 3.50(\mathrm{~d}, J=4.0 \mathrm{~Hz}, 1 \mathrm{H}), 3.69(\mathrm{~s}, 3 \mathrm{H}), 4.12(\mathrm{q}, J=4.0 \mathrm{~Hz}$, $2 \mathrm{H}), 4.32(\mathrm{~s}, 3 \mathrm{H}), 4.44(\mathrm{~d}, J=8.0 \mathrm{~Hz}, 1 \mathrm{H}), 4.58(\mathrm{t}, J=4.0 \mathrm{~Hz}, 2 \mathrm{H})$, $4.64(\mathrm{~d}, J=2.0 \mathrm{~Hz}, 1 \mathrm{H}), 4.72(\mathrm{~d}, J=8.0 \mathrm{~Hz}, 1 \mathrm{H}), 5.17(\mathrm{~s}, 1 \mathrm{H}), 6.32$ $(\mathrm{d}, J=4.0 \mathrm{~Hz}, 1 \mathrm{H}), 6.72(\mathrm{dd}, J=4.0,2.0 \mathrm{~Hz}, 1 \mathrm{H}), 7.32(\mathrm{~s}, 1 \mathrm{H}), 7.44$ $(\mathrm{d}, J=2.0 \mathrm{~Hz}, 1 \mathrm{H}) .{ }^{13} \mathrm{C} \mathrm{NMR}\left(100 \mathrm{MHz}, \mathrm{CDCl}_{3}\right) \delta 163.75,156.02$, $145.53,143.28,136.52,123.45,117.32,116.05,114.57,108.54$, $108.02,99.48,93.60,84.15,69.59,65.01,61.47,55.88,48.00,42.53$, $40.68,40.62,34.80,34.68,30.33,30.22,24.98,20.99,18.83,12.30$. HRMS-ESI: $\mathrm{m} / \mathrm{z}$ Calcd for $\mathrm{C}_{30} \mathrm{H}_{39} \mathrm{~N}_{5} \mathrm{O}_{8} \mathrm{Na}[\mathrm{M}+\mathrm{Na}]^{+}: 620.2691$; Found: 620.2674 .

3-(ethoxyimino)-5-methoxy-1-(2-(4-

$((((3 R, 5 \mathrm{aS}, 6 R, 8 \mathrm{aS}, 9 R, 12 R, 12 \mathrm{a} R)-3,6,9$-trimethyldecahydro- $12 \mathrm{H}$ 3,12-epoxy (Willis et al., 2019; Sławiński et al., 2020)dioxepino [4,3-i] isochromen-10-yl)oxy)methyl)-1H-1,2,3-triazol-1-yl) ethyl)indolin-2-one (9g).

Yellow solid, yield: $42 \%$. ${ }^{1} \mathrm{H}$ NMR $\left(400 \mathrm{MHz}, \mathrm{CDCl}_{3}\right) \delta$ 0.74-0.92 (m, 7H), 1.13-1.15 (m, 1H), 1.30-1.34 (m, 1H), 1.39 $(\mathrm{t}, J=4.0 \mathrm{~Hz}, 3 \mathrm{H}), 1.48-1.54(\mathrm{~m}, 5 \mathrm{H}), 1.56-1.61(\mathrm{~m}, 2 \mathrm{H})$,
1.66-1.69 (m, 1H), 1.76-1.79 (m, 2H), $1.90(\mathrm{~d}, J=4.0 \mathrm{~Hz}$, $1 \mathrm{H}), 2.32-2.35(\mathrm{~m}, 1 \mathrm{H}), 3.51(\mathrm{~d}, J=4.0 \mathrm{~Hz}, 1 \mathrm{H}), 3.70(\mathrm{~s}, 3 \mathrm{H})$, $4.16(\mathrm{q}, J=4.0 \mathrm{~Hz}, 2 \mathrm{H}), 4.44(\mathrm{~d}, J=8.0 \mathrm{~Hz}, 1 \mathrm{H}), 4.50(\mathrm{q}, J=$ $4.0 \mathrm{~Hz}, 2 \mathrm{H}), 4.60(\mathrm{td}, J=4.0,2.0 \mathrm{~Hz}, 2 \mathrm{H}), 4.65(\mathrm{~d}, J=2.0 \mathrm{~Hz}, 1 \mathrm{H})$, $4.72(\mathrm{~d}, J=8.0 \mathrm{~Hz}, 1 \mathrm{H}), 5.17(\mathrm{~s}, 1 \mathrm{H}), 6.30(\mathrm{~d}, J=8.0 \mathrm{~Hz}, 1 \mathrm{H}), 6.72$ $(\mathrm{dd}, J=4.0,2.0 \mathrm{~Hz}, 1 \mathrm{H}), 7.31(\mathrm{~s}, 1 \mathrm{H}), 7.48(\mathrm{~d}, J=4.0 \mathrm{~Hz}, 1 \mathrm{H}) .{ }^{13} \mathrm{C}$ NMR $\left(100 \mathrm{MHz}, \mathrm{CDCl}_{3}\right) \delta 163.90,155.99,145.55,143.11,136.42$, $123.44,116.87,116.21,114.73,108.42,108.02$, 99.51, 93.60, 84.17, $73.35,69.62,61.49,55.85,48.06,42.55,40.69,40.64,34.80,34.70$, $30.33,30.23,24.99,21.00,18.83,14.71,12.32$. HRMS-ESI: $\mathrm{m} / \mathrm{z}$ Calcd for $\mathrm{C}_{31} \mathrm{H}_{41} \mathrm{~N}_{5} \mathrm{O}_{8} \mathrm{Na}[\mathrm{M}+\mathrm{Na}]^{+}$: 634.2848; Found: 634.2839 .

3-[(benzyloxy)imino]-5-methoxy-1-(2-(4-

$(((3 R, 5 \mathrm{aS}, 6 \mathrm{R}, 8 \mathrm{aS}, 9 \mathrm{R}, 12 \mathrm{R}, 12 \mathrm{a} R)-3,6,9$-trimethyldecahydro- $12 \mathrm{H}$ 3,12-epoxy (Willis et al., 2019; Sławiński et al., 2020)dioxepino [4,3-i] isochromen-10-yl)oxy)methyl)-1H-1,2,3-triazol-1-yl) ethyl)indolin-2-one (9h).

Yellow solid, yield: $41 \% .{ }^{1} \mathrm{H}$ NMR $\left(400 \mathrm{MHz}, \mathrm{CDCl}_{3}\right) \delta$ 0.73-0.90 (m, 7H), 1.12-1.15 (m, 1H), 1.28-1.33 (m, 1H), $1.48-1.56(\mathrm{~m}, 5 \mathrm{H}), 1.60-1.62(\mathrm{~m}, 2 \mathrm{H}), 1.66-1.69(\mathrm{~m}, 1 \mathrm{H})$, $1.76-1.79(\mathrm{~m}, 2 \mathrm{H}), 1.90(\mathrm{~d}, J=8.0 \mathrm{~Hz}, 1 \mathrm{H}), 2.31-2.34(\mathrm{~m}$, $1 \mathrm{H}), 3.50(\mathrm{~d}, J=4.0 \mathrm{~Hz}, 1 \mathrm{H}), 3.62(\mathrm{~s}, 1 \mathrm{H}), 4.16(\mathrm{q}, J=4.0 \mathrm{~Hz}$, $2 \mathrm{H}), 4.44(\mathrm{~d}, J=8.0 \mathrm{~Hz}, 1 \mathrm{H}), 4.58(\mathrm{td}, J=4.0,2.0 \mathrm{~Hz}, 2 \mathrm{H}), 4.66(\mathrm{~d}$, $J=4.0 \mathrm{~Hz}, 1 \mathrm{H}), 4.72(\mathrm{~d}, J=8.0 \mathrm{~Hz}, 1 \mathrm{H}), 5.17(\mathrm{~s}, 1 \mathrm{H}), 5.46(\mathrm{~s}, 1 \mathrm{H})$, $6.30(\mathrm{~d}, J=4.0 \mathrm{~Hz}, 1 \mathrm{H}), 6.70(\mathrm{dd}, J=4.0,2.0 \mathrm{~Hz}, 1 \mathrm{H}), 7.28-7.39$ $(\mathrm{m}, 6 \mathrm{H}), 7.44(\mathrm{~d}, J=2.0 \mathrm{~Hz}, 1 \mathrm{H}) .{ }^{13} \mathrm{C} \mathrm{NMR}\left(100 \mathrm{MHz}, \mathrm{CDCl}_{3}\right) \delta$ $163.79,156.01,145.56,143.70,136.54,135.97,128.67,128.61$, $128.44,123.45,117.25,116.13,114.78,108.52,108.02,99.51$, $93.62,84.16,79.61,69.62,61.49,55.77,48.04,42.54,40.71$, $40.63,34.80,34.69,20.33,30.23,24.98,21.00,18.83,12.32$. HRMS-ESI: $\mathrm{m} / \mathrm{z}$ Calcd for $\mathrm{C}_{36} \mathrm{H}_{43} \mathrm{~N}_{5} \mathrm{O}_{8} \mathrm{Na}[\mathrm{M}+\mathrm{Na}]^{+}$: 696.3004; Found: 696.2981.

5-fluoro-3-(hydroxyimino)-1-(2-(4$((((3 R, 5 \mathrm{a} S, 6 \mathrm{R}, 8 \mathrm{aS}, 9 \mathrm{R}, 12 \mathrm{R}, 12 \mathrm{a} R)-3,6,9$-trimethyldecahydro- $12 \mathrm{H}$ 3,12-epoxy (Willis et al., 2019; Sławiński et al., 2020)dioxepino [4,3-i] isochromen-10-yl)oxy)methyl)-1H-1,2,3-triazol-1-yl) ethyl)indolin-2-one (9i).

Yellow solid, yield: $67 \% .{ }^{1} \mathrm{H}$ NMR $\left(400 \mathrm{MHz}, \mathrm{CD}_{3} \mathrm{OD}\right) \delta$ $0.72-0.88(\mathrm{~m}, 7 \mathrm{H}), 1.11-1.13(\mathrm{~m}, 1 \mathrm{H}), 1.19-1.21(\mathrm{~m}, 1 \mathrm{H})$, $1.37-1.41(\mathrm{~m}, 4 \mathrm{H}), 1.48-1.59(\mathrm{~m}, 3 \mathrm{H}), 1.64-1.69(\mathrm{~m}, 2 \mathrm{H})$, $1.75-1.78(\mathrm{~m}, 1 \mathrm{H}), 2.28-2.30(\mathrm{~m}, 1 \mathrm{H}), 3.39(\mathrm{~d}, J=2.0 \mathrm{~Hz}$, $1 \mathrm{H}), 4.16(\mathrm{t}, J=4.0 \mathrm{~Hz}, 1 \mathrm{H}), 4.40(\mathrm{~d}, J=8.0 \mathrm{~Hz}, 1 \mathrm{H})$, $4.60-4.67(\mathrm{~m}, 4 \mathrm{H}), 5.16(\mathrm{~s}, 1 \mathrm{H}), 6.64(\mathrm{dd}, J=4.0,2.0 \mathrm{~Hz}, 1 \mathrm{H})$, $6.98(\mathrm{td}, J=8.0,2.0 \mathrm{~Hz}, 1 \mathrm{H}), 7.66(\mathrm{dd}, J=8.0,2.0 \mathrm{~Hz}, 1 \mathrm{H}), 7.80(\mathrm{~s}$, $1 \mathrm{H}) .{ }^{13} \mathrm{C}$ NMR $\left(100 \mathrm{MHz}, \mathrm{CD}_{3} \mathrm{OD}\right) \delta 164.50,159.72(\mathrm{~J}=$ $198.75 \mathrm{~Hz}), 144.84,142.97,138.62,124.46,117.69,117.53$, $116.17,114.39,114.21,109.14,109.09,107.92,98.97,93.51$, $83.73,68.64,60.32,42.10,40.67,40.03,34.52,30.24,30.13$, 24.80, 20.02, 17.88, 11.28. HRMS-ESI: $\mathrm{m} / \mathrm{z}$ Calcd for $\mathrm{C}_{28} \mathrm{H}_{34} \mathrm{FN}_{5} \mathrm{O}_{7} \mathrm{Na}[\mathrm{M}+\mathrm{Na}]^{+}$: 594.2335; Found: 594.2330.

5-fluoro-3-(methoxyimino)-1-(2-(4-

$(((3 R, 5 \mathrm{aS}, 6 \mathrm{R}, 8 \mathrm{aS}, 9 \mathrm{R}, 12 \mathrm{R}, 12 \mathrm{a} R)-3,6,9$-trimethyldecahydro- $12 \mathrm{H}$ 3,12-epoxy (Willis et al., 2019; Sławiński et al., 2020)dioxepino [4,3-i] isochromen-10-yl)oxy)methyl)-1H-1,2,3-triazol-1-yl) ethyl)indolin-2-one (9j).

Yellow solid, yield: $52 \%$. ${ }^{1} \mathrm{H}$ NMR $\left(400 \mathrm{MHz}, \mathrm{CDCl}_{3}\right) \delta$ 0.74-0.90 (m, 7H), 1.13-1.15 (m, 1H), 1.30-1.33 (m, 1H), $1.48-1.56(\mathrm{~m}, 6 \mathrm{H}), 1.60-1.63(\mathrm{~m}, 1 \mathrm{H}), 1.68-1.71(\mathrm{~m}, 1 \mathrm{H})$, 
1.76-1.80 (m, 2H), $1.88(\mathrm{~d}, J=8.0 \mathrm{~Hz}, 1 \mathrm{H}), 2.33-2.35(\mathrm{~m}, 1 \mathrm{H})$, $3.50(\mathrm{dd}, J=8.0,4.0 \mathrm{~Hz}, 1 \mathrm{H}), 4.15-4.25(\mathrm{~m}, 4 \mathrm{H}), 4.44(\mathrm{~d}, J=$ $8.0 \mathrm{~Hz}, 1 \mathrm{H}), 4.60(\mathrm{t}, J=4.0 \mathrm{~Hz}, 1 \mathrm{H}), 4.65(\mathrm{~d}, J=4.0 \mathrm{~Hz}, 1 \mathrm{H}), 4.74$ $(\mathrm{d}, J=8.0 \mathrm{~Hz}, 1 \mathrm{H}), 5.18(\mathrm{~s}, 1 \mathrm{H}), 6.34(\mathrm{dd}, J=4.0,2.0 \mathrm{~Hz}, 1 \mathrm{H}), 6.90$ $(\mathrm{t}, J=4.0 \mathrm{~Hz}, 1 \mathrm{H}), 7.30(\mathrm{~s}, 1 \mathrm{H}), 7.58(\mathrm{dd}, J=4.0,2.0 \mathrm{~Hz}, 1 \mathrm{H}) .{ }^{13} \mathrm{C}$ NMR $\left(100 \mathrm{MHz}, \mathrm{CDCl}_{3}\right) \delta 174.32,159.74(J=198.75 \mathrm{~Hz}), 145.63$, $123.46,118.98,118.54,108.03,99.48,93.95,84.15,69.63,65.25$, $61.48,48.00,42.52,40.78,40.62,34.82,30.32,30.22,24.98,20.98$, 18.83, 12.27. HRMS-ESI: $\mathrm{m} / \mathrm{z}$ Calcd for $\mathrm{C}_{29} \mathrm{H}_{36} \mathrm{FN}_{5} \mathrm{O}_{7} \mathrm{Na}[\mathrm{M}+$ $\mathrm{Na}]^{+}:$608.2491; Found: 608.2483.

3-(ethoxyimino)-5-fluoro-1-(2-(4-

$((((3 R, 5 \mathrm{a} S, 6 R, 8 \mathrm{a} S, 9 R, 12 R, 12 \mathrm{a} R)-3,6,9$-trimethyldecahydro- $12 H$ 3,12-epoxy (Willis et al., 2019; Sławiński et al., 2020)dioxepino [4,3-i] isochromen-10-yl)oxy)methyl)-1H-1,2,3-triazol-1-yl) ethyl)indolin-2-one (9k).

Yellow solid, yield: $33 \%$. ${ }^{1} \mathrm{H}$ NMR $\left(400 \mathrm{MHz}, \mathrm{CDCl}_{3}\right) \delta$ 0.73-0.90 (m, 7H), 1.16-1.18 (m, 1H), 1.32-1.33 (m, 1H), 1.40 $(\mathrm{t}, J=4.0 \mathrm{~Hz}, 3 \mathrm{H}), 1.48-1.56(\mathrm{~m}, 5 \mathrm{H}), 1.60-1.70(\mathrm{~m}, 3 \mathrm{H})$, $1.76-1.80(\mathrm{~m}, 2 \mathrm{H}), 1.92(\mathrm{~d}, J=8.0 \mathrm{~Hz}, 1 \mathrm{H}), 2.33-2.35(\mathrm{~m}$, $1 \mathrm{H}), 3.49-3.51(\mathrm{~m}, 1 \mathrm{H}), 4.17-4.20(\mathrm{~m}, 2 \mathrm{H}), 4.44(\mathrm{~d}, J=$ $8.0 \mathrm{~Hz}, 1 \mathrm{H}), 4.50(\mathrm{q}, J=4.0 \mathrm{~Hz}, 2 \mathrm{H}), 4.60(\mathrm{t}, J=4.0 \mathrm{~Hz}, 1 \mathrm{H})$, $4.66(\mathrm{~d}, J=4.0 \mathrm{~Hz}, 1 \mathrm{H}), 4.74(\mathrm{~d}, J=8.0 \mathrm{~Hz}, 1 \mathrm{H}), 5.18(\mathrm{~s}, 1 \mathrm{H}), 6.34$ $(\mathrm{dd}, J=4.0,2.0 \mathrm{~Hz}, 1 \mathrm{H}), 6.88(\mathrm{t}, J=4.0 \mathrm{~Hz}, 1 \mathrm{H}), 7.31(\mathrm{~s}, 1 \mathrm{H}), 7.60$ $(\mathrm{dd}, J=4.0,2.0 \mathrm{~Hz}, 1 \mathrm{H}) .{ }^{13} \mathrm{C} \mathrm{NMR}\left(100 \mathrm{MHz}, \mathrm{CDCl}_{3}\right) \delta 163.77$, $159.68(J=200.00 \mathrm{~Hz}), 145.60,142.44,138.82,123.49,118.83$, $118.67,116.03,115.43,115.26,108.72,108.66,108.03,99.46$, $93.64,84.14,73.69,69.61,61.46,48.05,42.51,40.77,40.61$, $34.82,34.68,30.33,30.22,24.98,20.98,18.82,14.69,12.28$. HRMS-ESI: $\mathrm{m} / \mathrm{z}$ Calcd for $\mathrm{C}_{30} \mathrm{H}_{38} \mathrm{FN}_{5} \mathrm{O}_{7} \mathrm{Na}[\mathrm{M}+\mathrm{Na}]^{+}$: 622.2648; Found: 622.2630.

\section{Antiproliferative Activity}

A549, A549/DOX, and A549/DDP lung cancer cells $\left(2 \times 10^{3}\right)$ were plated in each well of a 96-well plate and were allowed to adhere and spread for $24 \mathrm{~h}$. The 1,2,3-triazole tethered dihydroartemisinin-isatin hybrids $8 \mathrm{a}-\mathrm{c}$ and $9 \mathrm{a}-\mathrm{k}$ were added to a final concentration of $100 \mu \mathrm{M}$, and the cells were cultured for $24 \mathrm{~h}$ at $\quad 37^{\circ} \mathrm{C}$. 3-(4,5-dimethyl-2-thiazolyl)-2,5-diphenyltetrazolium bromide (MTT) solution $(10 \mu \mathrm{L})$ was added to each well, and the cultures were incubated for an additional $4 \mathrm{~h}$. A further $100 \mu \mathrm{L}$ of MTT solution was added and incubation continued overnight. The absorbance at $540 \mathrm{~nm}$ was determined in each well with a 96well plate reader. The growth of the treated cells was compared with that of untreated cells.

\section{Cytotoxicity}

The cytotoxicity $\left(\mathrm{CC}_{50}\right)$ of the synthesized 1,2,3-triazole tethered dihydroartemisinin-isatin hybrids $8 \mathrm{a}-\mathrm{c}$ and $9 \mathrm{a}-\mathrm{k}$ were examined by the MTT assay in mouse embryonic fibroblast cells NIH/3T3. The compounds were dissolved in DMSO with concentrations from 1,024 to $1 \mu \mathrm{g} / \mathrm{ml}$. The $\mathrm{NIH} / 3 \mathrm{~T} 3$ cells were maintained in culture medium at $37^{\circ} \mathrm{C}$ under $5 \% \mathrm{CO}_{2}$ atmosphere. Cells were seeded in 96-well plates $\left(1 \times 10^{4}\right.$ cell per well $)$ and allowed to recover for $24 \mathrm{~h}$. After $72 \mathrm{~h}$ of exposure, cells were harvested and cell viability was assessed by MTT assay. The $\mathrm{CC}_{50}$ values were calculated by Bliss analy.

\section{Pharmacokinetic Profiles Determination}

CD-1 mice (20-25 g) were used in the pharmacokinetic study, and each treatment group had 3 mice which were dosed with hybrids $8 \mathrm{a}, \mathrm{c}$ suspension at $30 \mathrm{mg} / \mathrm{kg}$ by single intravenous administration. Compounds were suspended in $0.5 \% \mathrm{CMC}$ for iv, and blood was collected from the jugular vein of each mouse at the following time points: $0.25,0.5,1,2,4,6,8$ and $24 \mathrm{~h}$ after intravenous administration. Total area under the concentration time curve (AUC), the elimination half-time $\left(t_{1 / 2}\right)$, the peak concentration $\left(\mathrm{C}_{\max }\right)$ and the time to reach peak concentration $\left(\mathrm{T}_{\max }\right)$ of samples were determined directly from the experimental data using WinNonlin V6.2.1.

\section{DATA AVAILABILITY STATEMENT}

The original contributions presented in the study are included in the article/Supplementary Material, further inquiries can be directed to the corresponding author.

\section{ETHICS STATEMENT}

The animal study was reviewed and approved by The Animal Care and Use Committee of Shandong University with the corresponding ethical approval code (LL-201602040, 20162022).

\section{AUTHOR CONTRIBUTIONS}

All authors listed have made a substantial, direct, and intellectual contribution to the work and approved it for publication.

\section{FUNDING}

This research was funded by grants from the National Natural Science Foundation of China (81371601) and Natural Science Foundation of Shandong Province (ZR2019MH019, ZR2019BA015). This work gained great support by Translational Medicine Core Facility of Shandong University.

\section{SUPPLEMENTARY MATERIAL}

The Supplementary Material for this article can be found online at: https://www.frontiersin.org/articles/10.3389/fphar.2021.801580/ full\#supplementary-material 


\section{REFERENCES}

Bade, B. C., and Dela Cruz, C. S. (2020). Lung Cancer 2020. Clin. Chest Med. 41 (1), 1-24. doi:10.1016/j.ccm.2019.10.001

Chen, L., Zhao, Y., Halliday, G. C., Berry, P., Rousseau, R. F., Middleton, S. A., et al. (2014). Structurally Diverse MDM2-P53 Antagonists Act as Modulators of MDR-1 Function in Neuroblastoma. Br. J. Cancer 111, 716-725. doi:10.1038/bjc.2014.325

Coakley, M., and Popat, S. (2020). Management of Lung Cancer. Medicine 48 (4), 273-278. doi:10.1016/j.mpmed.2020.01.003

Dai, Y.-F., Zhou, W.-W., Meng, J., Du, X.-L., Sui, Y.-P., Dai, L., et al. (2017). The Pharmacological Activities and Mechanisms of Artemisinin and its Derivatives: A Systematic Review. Med. Chem. Res. 26, 867-880. doi:10.1007/s00044-016-1778-5

Ding, Z., Zhou, M., and Zeng, C. (2020). Recent Advances in Isatin Hybrids as Potential Anticancer Agents. Arch. Pharm. (Weinheim) 353 (3), e1900367. doi:10.1002/ardp.201900367

Feng, L. S., Xu, Z., Chang, L., Li, C., Yan, X. F., Gao, C., et al. (2020). Hybrid Molecules with Potential In Vitro Antiplasmodial and In Vivo Antimalarial Activity against Drug-Resistant Plasmodium Falciparum. Med. Res. Rev. 40 (3), 931-971. doi:10.1002/med.21643

Gao, F., Sun, Z., Kong, F., and Xiao, J. (2020). Artemisinin-derived Hybrids and Their Anticancer Activity. Eur. J. Med. Chem. 188, 112044. doi:10.1016/ j.ejmech.2020.112044

Gray, M. E., Meehan, J. s., Sullivan, P., Marland, J. R. K., Greenhalgh, S. N., Gregson, R., et al. (2019). Ovine Pulmonary Adenocarcinoma: A Unique Model to Improve Lung Cancer Research. Front. Oncol. 9, e335. doi:10.3389/fonc.2019.00335

He, C., Liu, D., and Lin, W. (2015). Self-assembled Nanoscale Coordination Polymers Carrying siRNAs and Cisplatin for Effective Treatment of Resistant Ovarian Cancer. Biomaterials 36, 124-133. doi:10.1016/ j.biomaterials.2014.09.017

He, C., Poon, C., Chan, C., Yamada, S. D., and Lin, W. (2016). Nanoscale Coordination Polymers Codeliver Chemotherapeutics and siRNAs to Eradicate Tumors of Cisplatin-Resistant Ovarian Cancer. J. Am. Chem. Soc. 138, 6010-6019. doi:10.1021/jacs.6b02486

Hirsch, F. R., Scagliotti, G. V., Mulshine, J. L., Kwon, R., Curran, W. J., Wu, Y. L., et al. (2017). Lung Cancer: Current Therapies and New Targeted Treatments. Lancet 389 (10066), 299-311. doi:10.1016/S0140-6736(16)30958-8

Hou, Y., Shang, C., Wang, H., and Yun, J. (2020). Isatin-azole Hybrids and Their Anticancer Activities. Arch. Pharm. (Weinheim) 353 (1), e1900272. doi:10.1002/ardp.201900272

Kang, X., Yu, Y., Chen, Z., Wu, Y., Wei, D., Zhao, Y., et al. (2019). A Negatively Charged Pt(iv) Prodrug for Electrostatic Complexation with Polymers to Overcome Cisplatin Resistance. J. Mater. Chem. B 7, 3346-3350. doi:10.1039/c9tb00155g

Kiani, B. H., Kayani, W. K., Khayam, A. U., Dilshad, E., Ismail, H., and Mirza, B. (2020). Artemisinin and its Derivatives: a Promising Cancer Therapy. Mol. Biol. Rep. 47 (8), 6321-6336. doi:10.1007/s11033-020-05669-z

Li, D., Zhang, J., and Zhao, X. (2021). Mechanisms and Molecular Targets of Artemisinin in Cancer Treatment. Cancer Invest. 39 (8), 675-684. doi:10.1080/ 07357907.2021.1954190

Nascimento, A. V., Singh, A., Bousbaa, H., Ferreira, D., Sarmento, B., and Amiji, M. M. (2017). Overcoming Cisplatin Resistance in Non-small Cell Lung Cancer with Mad2 Silencing siRNA Delivered Systemically Using EGFR-Targeted Chitosan Nanoparticles. Acta Biomater. 47, 71-80. doi:10.1016/j.actbio.2016.09.045

Nath, P., Mukherjee, A., Mukherjee, S., Banerjee, S., Das, S., and Banerjee, S. (2021). Isatin: A Scaffold with Immense Biodiversity. Mini Rev. Med. Chem. 21 (9), 1096-1112. doi:10.2174/2211536609666201125115559

Nepali, K., Sharma, S., Sharma, M., Bedi, P. M., and Dhar, K. L. (2014). Rational Approaches, Design Strategies, Structure Activity Relationship and Mechanistic Insights for Anticancer Hybrids. Eur. J. Med. Chem. 77, 422-487. doi:10.1016/ j.ejmech.2014.03.018

Oak, C. H., Wilson, D., Lee, H. J., Lim, H. J., and Park, E. K. (2012). Potential Molecular Approaches for the Early Diagnosis of Lung Cancer (Review). Mol. Med. Rep. 6 (5), 931-936. doi:10.3892/mmr.2012.1042

Saadeh, H. A., and Mubarak, M. S. (2017). Hybrid Drugs as Potential Combatants against Drug-Resistant Microbes: A Review. Curr. Top. Med. Chem. 17 (8), 895-906. doi:10.2174/1568026616666160927155251

Schegoleva, A. A., Khozyainova, A. A., Fedorov, A. A., Gerashchenko, T. S., Rodionov, E. O., Topolnitsky, E. B., et al. (2021). Prognosis of Different
Types of Non-small Cell Lung Cancer Progression: Current State and Perspectives. Cell Physiol. Biochem. 55, 29-48. doi:10.33594/000000340

Sharma, M., Sharma, S., Buddhiraja, A., Saxena, A. K., Nepali, K., and Bedi, P. M. S. (2014). Synthesis and Cytotoxicity Studies of 3,5-diaryl N-Acetyl Pyrazoline-Isatin Hybrids. Med. Chem. Res. 23, 4337-4344. doi:10.1007/s00044-014-1001-5

Sharma, S., Gupta, M. K., Saxena, A. K., and Bedi, P. M. (2015). Triazole Linked Mono Carbonyl Curcumin-Isatin Bifunctional Hybrids as Novel Anti Tubulin Agents: Design, Synthesis, Biological Evaluation and Molecular Modeling Studies. Bioorg. Med. Chem. 23 (22), 7165-7180. doi:10.1016/j.bmc.2015.10.013 Siegel, R. L., Miller, K. D., Fuchs, H. E., and Jemal, A. (2021). Cancer Statistics, 2021. CA A. Cancer J. Clin. 71 (1), 7-33. doi:10.3322/caac.21654

Singh, H., Kumar, M., Nepali, K., Gupta, M. K., Saxena, A. K., Sharma, S., et al. (2016). Triazole Tethered C5-Curcuminoid-Coumarin Based Molecular Hybrids as Novel Antitubulin Agents: Design, Synthesis, Biological Investigation and Docking Studies. Eur. J. Med. Chem. 116, 102-115. doi:10.1016/j.ejmech.2016.03.050

Singh, H., Singh, J. V., Gupta, M. K., Saxena, A. K., Sharma, S., Nepali, K., et al. (2017). Triazole Tethered Isatin-Coumarin Based Molecular Hybrids as Novel Antitubulin Agents: Design, Synthesis, Biological Investigation and Docking Studies. Bioorg. Med. Chem. Lett. 27 (17), 3974-3979. doi:10.1016/j.bmcl.2017.07.069

Singh, J., Sharma, S., Saxena, A. K., Nepali, K., and Bedi, P. M. S. (2013). Synthesis of 1,2,3triazole Tethered Bifunctional Hybrids by Click Chemistry and Their Cytotoxic Studies. Med. Chem. Res. 22, 3160-3169. doi:10.1007/s00044-012-0312-7

Sławiński, G., Wrona, A., Dąbrowska-Kugacka, A., Raczak, G., and Lewicka, E. (2020). Immune Checkpoint Inhibitors and Cardiac Toxicity in Patients Treated for Non-small Lung Cancer: A Review. Int. J. Mol. Sci. 21 (19), e7195. doi:10.3390/ijms21197195

Tong, Y., Liu, Y., Zheng, H., Zheng, L., Liu, W., Wu, J., et al. (2016). Artemisinin and its Derivatives Can Significantly Inhibit Lung Tumorigenesis and Tumor Metastasis through Wnt/ß-Catenin Signaling. Oncotarget 7 (21), 31413-31428. doi:10.18632/oncotarget.8920

Varpe, B. D., Kulkarni, A. A., Jadhav, S. B., Mali, A. S., and Jadhav, S. Y. (2021) Isatin Hybrids and Their Pharmacological Investigations. Mini Rev. Med. Chem. 21 (10), 1182-1225. doi:10.2174/1389557520999201209213029

Wen, T., Song, L., and Hua, S. (2021). Perspectives and Controversies Regarding the Use of Natural Products for the Treatment of Lung Cancer. Cancer Med. 10 (7), 2396-2422. doi:10.1002/cam4.3660

Willis, C., Fiander, M., Tran, D., Korytowsky, B., Thomas, J. M., Calderon, F., et al. (2019). Tumor Mutational burden in Lung Cancer: A Systematic Literature Review. Oncotarget 10 (61), 6604-6622. doi:10.18632/oncotarget.27287

Yan, Y., Björnmalm, M., and Caruso, F. (2013). Particle Carriers for Combating Multidrug-Resistant Cancer. ACS Nano 7, 9512-9517. doi:10.1021/nn405632s

Yu, P., Li, Z., Wang, P., and Sun, H. (2019). Advances in Anti-tumor Effects of Artemisinin and its Derivatives. Anti-tumor Pharm. 9 (4), 534-539.

Zhang, Q., Yi, H., Yao, H., Lu, L., He, G., Wu, M., et al. (2021). Artemisinin Derivatives Inhibit Non-small Cell Lung Cancer Cells through Induction of ROS-dependent Apoptosis/ferroptosis. J. Cancer 12 (13), 4075-4085. doi:10.7150/jca.57054

Zhu, S., Yu, Q., Huo, C., Li, Y., He, L., Ran, B., et al. (2021). Ferroptosis: A Novel Mechanism of Artemisinin and its Derivatives in Cancer Therapy. Curr. Med. Chem. 28 (2), 329-345. doi:10.2174/ 0929867327666200121124404

Conflict of Interest: The authors declare that the research was conducted in the absence of any commercial or financial relationships that could be construed as a potential conflict of interest.

Publisher's Note: All claims expressed in this article are solely those of the authors and do not necessarily represent those of their affiliated organizations, or those of the publisher, the editors and the reviewers. Any product that may be evaluated in this article, orclaim that may be made by its manufacturer, is not guaranteed or endorsed by the publisher.

Copyright (C) $2021 \mathrm{Hou}, \mathrm{Qu}, \mathrm{Su}, \mathrm{Hou}$ and Gao. This is an open-access article distributed under the terms of the Creative Commons Attribution License (CC BY). The use, distribution or reproduction in other forums is permitted, provided the original author(s) and the copyright owner(s) are credited and that the original publication in this journal is cited, in accordance with accepted academic practice. No use, distribution or reproduction is permitted which does not comply with these terms. 